\title{
Knowledge and perception on tuberculosis transmission in Tanzania: Multinomial logistic regression analysis of secondary data
}

\author{
ABBAS ISMAIL * and PETER JOSEPHAT \\ Department of Statistics, College of Natural and Mathematical Sciences, University of Dodoma, Tanzania, P.O. \\ Box 338, Dodoma, Tanzania
}

\begin{abstract}
Tuberculosis (TB) is one of the most important public health problems in Tanzania and was declared as a national public health emergency in 2006. Community and individual knowledge and perceptions are critical factors in the control of the disease. The objective of this study was to analyze the knowledge and perception on the transmission of TB in Tanzania. Multinomial Logistic Regression analysis was considered in order to quantify the impact of knowledge and perception on TB. The data used was adopted as secondary data from larger national survey 2007-08 Tanzania HIV/AIDS and Malaria Indicator Survey. The findings across groups revealed that knowledge on TB transmission increased with an increase in age and level of education. People in rural areas had less knowledge regarding tuberculosis transmission compared to urban areas [OR=0.7]. People with the access to radio [OR=1.7] were more knowledgeable on tuberculosis transmission compared to those who did not have access to radio. People who did not have telephone $[\mathrm{OR}=0.6]$ were less knowledgeable on tuberculosis route of transmission compared to those who had telephone. The findings showed that socio-demographic factors such as age, education, place of residence and owning telephone or radio varied systematically with knowledge on tuberculosis transmission.
\end{abstract}

Keywords: Tuberculosis, transmission, multinomial logistic regression, perception, knowledge, Tanzania

\section{Introduction}

The magnitude of Tuberculosis (TB) remains high worldwide especially in developing countries. It is the second killer worldwide after HIV due to its single infectious agent. In 2012, about 8.6 million people had TB and among them, 1.3 million people (15.1\%) died (WHO, 2013). In recent years, the vast majority of tuberculosis cases (95\%) and deaths (98\%) were from developing countries (Ristić et al., 2010). Although all age groups are at risk, the disease mostly affects young adults (Dodor, 2008; Ristić et al., 2010; WHO, 2013). The disease is still an important public health problem in Tanzania with a prevalence of bacteriological TB of 295 per 100,000 adult populations (MoHSW, 2013).

Studies have shown that, a successful tuberculosis control requires proper and timely diagnosis as well as efficacy anti-TB drugs among other factors (Ristić et al., 2010). This suggests that drugs are not only the way of controlling TB but other factors such as knowledge and perception play a role in preventing and controlling TB. The correct knowledge and positive perception of the community towards $\mathrm{TB}$ and its management is a prerequisite to early treatment seeking (Mangesho et al., 2007).

Early case identification and adherence to treatment regimens are the remaining barriers to successful control. Rubel \& Garro (1992) have identified costs of transportation to clinic services, the socio-cultural factors including stigma that attaches to tuberculosis, the high cost of medication, organizational problems in providing adequate follow-up services, and patients' perception to contribute to delays in seeking care among TB patients.

The significance of TB diagnosis is very important in early stages as a complement to early treatment. If not treated in the earliest five years, about $50 \%$ of cases die (Dodor, 2008). The delays in seeking care for TB have been associated with stigma. In some parts, it has been considered as a dirty disease which mainly affects poor people (Kilale et al., 2008). The TB related pervasive stigma worsens the quality of life of its victims. Because of this, patients may hide their

\footnotetext{
* Correspondence: Abbas Ismail; Email: E-mail: abbasism2003@yahoo.co.uk
} 
symptoms or diagnosis, and feel guilt and shame (Karim et al., 2011). Beliefs about health and the perceived severity of TB are vital determinants of early help seeking and diagnosis (Karim et al., 2011). Misperception of the diseases can create stigma and panic in the community. In addition, lack of awareness or incorrect knowledge may affect timely reporting and poor compliance (Eram et al., 2006).

Because of the importance of knowledge and perception on TB, there have been rigorous studies focusing on knowledge and perception of TB so as to develop strategies to minimize the effects on patient (Dodor, 2008). By taking into account, the role of knowledge and perception in controlling the disease, the objective of this paper was to analyze the knowledge and perception on TB transmission in Tanzania. Multinomial Logistic Regression analysis was considered in order to quantify the impact of knowledge and perception on TB.

\section{Material and Methods}

\section{Source of data}

The study adopted secondary data from the Tanzania HIV/AIDS and Malaria Indicator Survey of 2007-2008. The study sample consisted of 16,318 individual household members. The study included variables about knowledge and perceptions on ways tuberculosis is transmitted from both individual and household questionnaires of THMIS. In this study, the outcome variable (TB transmission from person to person) had seven categories (through air when coughing, through sharing utensils, through touching a person with TB, through food, through sexual contact, through mosquito bites and do not know). The explanatory variables included having radio, level of education, place of residence, age of respondents, having television, having telephone, respondents' working status, heard of tuberculosis, treatment on tuberculosis and keeping secret when family member gets TB.

\section{Data analysis}

The paper adopted both descriptive and inferential analysis. The descriptive analysis was done in order to obtain the preliminary information of the study sample. The frequency distribution tables were initially presented to describe the study sample of the study area. Chi-square was used to assess the distributional characteristics of the data and as the prerequisite information for multivariate analysis. It was used as the test of association at $5 \%$ level of significance between the outcome and explanatory variables, only significant variables were retained for further analysis. Later, multinomial logistic regression analysis was applied to give the functional relationship of the variables.

There were $n=16,318$ independent observations with $p=11$ explanatory variables. The qualitative response variable has $k=7$ categories. To construct the logits in the multinomial case, one of the categories is considered as the base level and all the logits were constructed relative to it. Any category can be taken as the base level but in this case, the reference category is response "do not know how TB is transmitted". The category "do not know" was taken as the base level in our description of the method. Let $\pi_{j}$ denote the multinomial probability of an observation falling in the $j^{\text {th }}$ category. The issue of interest was to find the relationship between this probability and the $p$-explanatory variables $X_{1}, X_{2}, \ldots \ldots \ldots, X_{p}$. The logistic regression model was then given by:

$$
\begin{array}{r}
\log _{e}\left(\frac{\pi_{j}\left(x_{i}\right)}{\pi_{k}\left(x_{i}\right)}\right)=\beta_{o j}+\beta_{1 j} x_{1 i}+\beta_{2 j} x_{2 i}+\ldots \ldots+\beta_{11 j} x_{11 i}, \text { where } j=1,2,3 \ldots \ldots ., k-1 \\
\text { and } i=1,2, \ldots ., n
\end{array}
$$

Whereby: 
$x_{1 i}=$ Having radio, $x_{2 i}=$ level of education, $x_{3 i}=$ place of residence, $x_{4 i}=$ age of respondents, $x_{5 i}$ =having television, $x_{6 i}=$ having telephone, $x_{7 i}=$ respondents' working status, $x_{8 i}=$ watched/heard HIV education programme on TV or radio in last 12 months, $x_{9 i}=$ heard of tuberculosis, $x_{10 i}=$ treatment on tuberculosis and $x_{11 i}=$ keeping secret when family member gets TB $\beta_{0 j}=$ Constant and $\beta_{1 j}, \beta_{2 j}, \beta_{3 j}, \ldots \ldots . ., \beta_{11 j}=$ Coefficients corresponding to explanatory variables.

Since all the $\pi_{j}$ 's add to unity, the equation above reduces to

$$
\log _{e}\left(\pi_{j}\left(x_{i}\right)\right)=\frac{\exp \left(\beta_{o j}+\beta_{1 j} x_{1 i}+\beta_{2 j} x_{2 i}+\ldots \ldots+\beta_{p j} x_{p i}\right)}{1+\sum_{j=i}^{k-1} \exp \left(\beta_{o j}+\beta_{1 j} x_{1 i}+\beta_{2 j} x_{2 i}+\ldots . .+\beta_{p j} x_{p i}\right)}
$$

\section{Results}

\section{Descriptive Analysis}

Over half $(57.3 \%)$ of the respondents were females. About a quarter $(24.6 \%)$ of the respondents were 15-19 years old. People aged above 45 years accounted for the minority (8.1\%) of the respondents (Table 1).

Table 1: Demographic characteristics of respondents $(n=16,318)$

\begin{tabular}{llll}
\hline Covariate & Response & Number & Description Value (\%) \\
\hline Sex & Male & 6,975 & 42.7 \\
Age of respondents & Female & 9,343 & 57.3 \\
& $15-19$ & 4,019 & 24.6 \\
& $20-24$ & 2,827 & 17.3 \\
& $25-29$ & 2,445 & 15.0 \\
& $30-34$ & 2,250 & 13.8 \\
Residence & $35-39$ & 1,988 & 12.2 \\
& $40-44$ & 1,473 & 9.0 \\
Education level & $45-49$ & 1,316 & 8.1 \\
& Urban & 3,671 & 22.5 \\
& Rural & 12,647 & 77.5 \\
Employment & No education & 2,882 & 17.7 \\
& Primary education & 10,403 & 63.8 \\
& Secondary school & 2,765 & 16.9 \\
\hline
\end{tabular}

The findings indicated that the distribution of males and females for the sample was slightly skewed with females and youths accounting for the larger proportion of the respondents. Majority of the respondents had primary level of education (63.8\%) as compared to the rest of the respondents. The respondents from rural areas accounted for over three quarters $(77.5 \%)$ of the total respondents. Those respondents who were either self-employed or employees occupied $71.1 \%$ of the total respondents and those who were not working occupied $28.9 \%$ of the total respondents (Table 1). 
Table 2: Respondent's possession of radio, television and telephone $(n=16,318)$

\begin{tabular}{l|l|l}
\hline Covariate & Response & Description Value (\%) \\
\hline Has radio & No & $5,332(32.7 \%)$ \\
& Yes & $10,154(62.2 \%)$ \\
Has television & Not de jure resident & $828(5.1 \%)$ \\
& No & $13,571(83.2 \%)$ \\
Has telephone & Yes & $1,910(11.7 \%)$ \\
& Not de jure resident & $828(05.1 \%)$ \\
& No & $15,299(93.9 \%)$ \\
& Yes & $174(01.1 \%)$ \\
\hline
\end{tabular}

The study showed that majority of the respondents owned radio regardless of what type of radio and only a small proportion (11.7\%) had a television set. The majority $(80.6 \%)$ of the respondents agreed that tuberculosis can be cured but over three quarters $(76.4 \%)$ could not agree to keep secret when family member gets TB (Table 3 ).

Table 3: Respondents knowledge of Tuberculosis $(n=16,318)$

\begin{tabular}{lll}
\hline Covariate & Response & Description Value (\%) \\
\hline Heard of Tuberculosis & No & $787(04.8 \%)$ \\
Tuberculosis is curable & Yes & $15,529(95.2 \%)$ \\
& No & $1,767(11.4 \%)$ \\
Keep secret when family member gets TB & Yes & $12,492(80.6 \%)$ \\
& Don't know & $1,232(8.0 \%)$ \\
& No & $11,655(76.4 \%)$ \\
& Yes & $3,313(21.7 \%)$ \\
\hline
\end{tabular}

\section{Bivariate analysis}

The findings showed that respondents with age between 15-19 years old were less likely to accept that TB spreads from person to person through air when coughing compared to those who aged 45-49 years old. Those aged between 20-24 years old were less likely to accept that TB spreads through air when coughing compared to those with age between $45-49$ years old. The respondents with the age between 25-29 years old were less likely to accept that TB spreads from person to person through air when coughing compared to those with age between 45-49 years old. Those with age between 30-34 years old were less likely to accept that TB spreads from person to person through air when coughing compared to those with age between 45-49 years old. Those with age between 35-39 years old were less likely to accept that TB spread from person to person through air when coughing compared to those with age between 45-49 years old. Those with the age between 40-44 years old were less likely to accept that TB spreads from person to person through air when coughing compared to those with age between 45-49 years old. Respondents aged between 15 and 44 years were less likely than those aged 45 years and above to accept that TB spreads from person to person through air when coughing (Table 5). The respondents who resided in rural areas were less likely to accept that TB spreads from person to person through air when coughing compared to those from urban areas (Table 5).

The respondents who had no education, those with primary and secondary education were less likely to accept that TB spreads from person to person through air when coughing compared to those with highest level of education. Respondents who had radio were more likely 
to accept that TB spreads from person to person through air when coughing compared to those who were not dejure residents.

Table 4: Cross tabulation of outcome variable versus explanatory variables

\begin{tabular}{|c|c|c|c|c|c|c|c|c|c|}
\hline \multirow[t]{2}{*}{ Covariate } & \multirow[t]{2}{*}{ Response } & \multicolumn{7}{|c|}{ Tuberculosis transmission from person to person } & \multirow[t]{2}{*}{ P-value } \\
\hline & & A & B & C & D & E & $\mathbf{F}$ & G & \\
\hline \multirow[t]{3}{*}{ Has radio } & No & $26.8 \%$ & $34.2 \%$ & $46.3 \%$ & $36.1 \%$ & $41.9 \%$ & $41.7 \%$ & $37.5 \%$ & 0.000 \\
\hline & Yes & $67.8 \%$ & $61.8 \%$ & $46.3 \%$ & $59.8 \%$ & $50.8 \%$ & $58.3 \%$ & $58.0 \%$ & \\
\hline & Not dejure resident & $05.4 \%$ & $04.0 \%$ & $07.3 \%$ & $04.1 \%$ & $07.3 \%$ & $0.00 \%$ & $04.5 \%$ & \\
\hline \multirow[t]{4}{*}{ Education } & No education & $10.0 \%$ & $18.2 \%$ & $22.2 \%$ & $28.4 \%$ & $24.2 \%$ & $08.3 \%$ & $23.7 \%$ & 0.000 \\
\hline & Primary & $62.6 \%$ & $71.0 \%$ & $63.4 \%$ & $64.4 \%$ & $68.5 \%$ & $25.0 \%$ & $62.2 \%$ & \\
\hline & Secondary & $24.7 \%$ & $09.9 \%$ & $12.2 \%$ & $07.2 \%$ & $07.3 \%$ & $58.3 \%$ & $13.8 \%$ & \\
\hline & Higher & $02.8 \%$ & $0.9 \%$ & $02.4 \%$ & $0.00 \%$ & $0.0 \%$ & $08.3 \%$ & $0.3 \%$ & \\
\hline \multirow[t]{2}{*}{ Residence } & Urban & $27.9 \%$ & $18.9 \%$ & $14.6 \%$ & $15 \cdot 5 \%$ & $17.7 \%$ & $08.3 \%$ & $16.1 \%$ & 0.000 \\
\hline & Rural & $72.1 \%$ & $81.1 \%$ & $85.4 \%$ & $84.5 \%$ & $82.3 \%$ & $91.7 \%$ & $83.9 \%$ & \\
\hline \multirow[t]{7}{*}{ Age } & $15-19$ & $25.7 \%$ & $16.3 \%$ & $17.1 \%$ & $14.9 \%$ & $29.8 \%$ & $08.3 \%$ & $25.4 \%$ & 0.000 \\
\hline & $20-24$ & $16.6 \%$ & $16.5 \%$ & $26.8 \%$ & $12.9 \%$ & $18.5 \%$ & $00.0 \%$ & $19.7 \%$ & \\
\hline & $25-29$ & $14.2 \%$ & $17.0 \%$ & $09.8 \%$ & $12.4 \%$ & $18.5 \%$ & $08.3 \%$ & $16.3 \%$ & \\
\hline & $30-34$ & $14.2 \%$ & $16.7 \%$ & $09.8 \%$ & $12.9 \%$ & $08.9 \%$ & $16.7 \%$ & $13.5 \%$ & \\
\hline & $35-39$ & $12.2 \%$ & $14.2 \%$ & $14.6 \%$ & $22.2 \%$ & $12.1 \%$ & $25.0 \%$ & $11.0 \%$ & \\
\hline & $40-44$ & $09.0 \%$ & $10.8 \%$ & $09.8 \%$ & $13.4 \%$ & $08.9 \%$ & $33.3 \%$ & $07.6 \%$ & \\
\hline & $45-49$ & $08.2 \%$ & $08.5 \%$ & $12.2 \%$ & $11.3 \%$ & $03.2 \%$ & $08.3 \%$ & $06.6 \%$ & \\
\hline \multirow[t]{3}{*}{ Has TV } & No & $78.9 \%$ & $86.3 \%$ & $80.5 \%$ & $91.2 \%$ & $87.9 \%$ & $91.7 \%$ & $87.7 \%$ & 0.000 \\
\hline & Yes & $15.7 \%$ & $09.7 \%$ & $12.2 \%$ & $04.6 \%$ & $04.8 \%$ & $08.3 \%$ & $07.8 \%$ & \\
\hline & Not dejure resident & $05.4 \%$ & $04.0 \%$ & $07.3 \%$ & $04.1 \%$ & $07.3 \%$ & $0.00 \%$ & $04.5 \%$ & \\
\hline \multirow[t]{3}{*}{ Has telephone } & No & $92.7 \%$ & $95.3 \%$ & $92.7 \%$ & $95.4 \%$ & $92.7 \%$ & $100 \%$ & $95.0 \%$ & 0.002 \\
\hline & Yes & $01.9 \%$ & $0.7 \%$ & $0.00 \%$ & $0.50 \%$ & $0.00 \%$ & $0.00 \%$ & $0.50 \%$ & \\
\hline & Not dejure resident & $05.4 \%$ & $04.0 \%$ & $07.3 \%$ & $04.1 \%$ & $07.3 \%$ & $0.00 \%$ & $04.5 \%$ & \\
\hline Currently & No & $31.6 \%$ & $21.5 \%$ & $22.0 \%$ & $23.7 \%$ & $25.8 \%$ & $16.7 \%$ & $28.8 \%$ & 0.000 \\
\hline Working & Yes & $68.4 \%$ & $78.5 \%$ & $78.0 \%$ & $76.3 \%$ & $74.2 \%$ & $83.3 \%$ & $71.2 \%$ & \\
\hline \multirow[t]{2}{*}{ Heard of TB } & No & $0.00 \%$ & $0.00 \%$ & $0.00 \%$ & $0.00 \%$ & $0.00 \%$ & $0.00 \%$ & $0.00 \%$ & \\
\hline & Yes & $100 \%$ & $100 \%$ & $100 \%$ & $100 \%$ & $100 \%$ & $100 \%$ & $100 \%$ & \\
\hline \multirow[t]{3}{*}{ TB is curable } & No & $08.7 \%$ & $13.0 \%$ & $19.5 \%$ & $12.4 \%$ & $35.0 \%$ & $0.00 \%$ & $15.0 \%$ & 0.002 \\
\hline & Yes & $87.4 \%$ & $83.7 \%$ & $80.5 \%$ & $81.9 \%$ & $56.1 \%$ & $83.3 \%$ & $70.4 \%$ & \\
\hline & Don't know & $03.9 \%$ & $03.3 \%$ & $0.00 \%$ & $05.7 \%$ & $08.9 \%$ & $16.7 \%$ & $14.6 \%$ & \\
\hline \multirow[t]{3}{*}{ Keep secret } & No & $80.4 \%$ & $77.9 \%$ & $82.9 \%$ & $72.3 \%$ & $54.1 \%$ & $91.7 \%$ & $71.4 \%$ & 0.000 \\
\hline & Yes & $18.8 \%$ & $21.6 \%$ & $14.6 \%$ & $25 \cdot 5 \%$ & $43.4 \%$ & $8.30 \%$ & $25.2 \%$ & \\
\hline & Don't know & $0.70 \%$ & $0.50 \%$ & $2.40 \%$ & $2.10 \%$ & $2.50 \%$ & $0.00 \%$ & $3.40 \%$ & \\
\hline
\end{tabular}

Keys: $A$ =through air when coughing; $B=$ through sharing utensils; $C=$ through touching person with TB; $D=$ through food; $E=$ through sexual contacts; $F=$ through mosquito bites; $F=$ don't know.

The respondents who did not have telephones were less likely to agree that TB spreads from person to person through air when coughing compared to those with telephones. Respondents who were employed were more likely to agree that TB spreads from person to person through air when coughing compared to those who were not employed. The respondents who believed that TB can be cured were more likely to accept that TB spreads from person to person through air when coughing compared to those respondents who did not know if TB is curable. Respondents who believed that TB cannot be cured were more likely to disagree that TB spreads from person to person through air when coughing compared to those who did not know if TB can be cured (Table 5).

The respondents who accepted to keep secret when family member gets TB were more likely to believe that TB spreads from person to person through air when coughing compared to those who were undecided whether to keep secret or reveal to the public. The respondents who were 15-24 years old were more likely to accept that TB spreads from person to person through sharing utensils compared to those aged above 45 years. The respondents who agreed that tuberculosis can be cured were less likely to accept that TB spreads from person to person 
through sharing utensils compared to those who did not know if tuberculosis can be cured. Respondents who agreed to keep secret when family member gets TB were more likely to believe that TB spreads from person to person through sharing utensils compared to those who did not know whether to keep secret or reveal to the public. The respondents with aged 15-24 years old were more likely to accept that TB spreads from person to person through food compared to those $>45$ years old.

Respondents who agreed that tuberculosis can be cured were less likely to accept that TB spreads from person to person through sexual contacts compared to those who did not know if tuberculosis curable. Respondents who did not have radio were more likely to accept that TB spreads from person to person through mosquito bites compared to respondents who were not dejure residents (Table 5).

\section{Inferential Analysis}

Table 5: Multinomial Logistic Regression of the ways Tuberculosis spread from person to person

\begin{tabular}{|c|c|c|c|c|c|c|c|}
\hline Variable & Cases & $\begin{array}{l}\text { Through air } \\
\text { when coughing }\end{array}$ & $\begin{array}{l}\text { ir Through } \\
\text { sharing } \\
\text { utensils }\end{array}$ & $\begin{array}{l}\text { Through } \\
\text { touching } \\
\text { person } \\
\text { with TB }\end{array}$ & $\begin{array}{l}\text { Through } \\
\text { food }\end{array}$ & $\begin{array}{l}\text { Through } \\
\text { sexual } \\
\text { contacts }\end{array}$ & $\begin{array}{l}\text { Through } \\
\text { mosquito }\end{array}$ \\
\hline \multirow{6}{*}{$\begin{array}{l}\text { Respondents age } \\
\text { (ref:45-49) }\end{array}$} & $15-19$ & $0.658^{* * *}$ & $1.508^{* * *}$ & 0.388 & $1.336^{* * *}$ & 2.474 & 0.195 \\
\hline & $20-24$ & $0.501^{* * *}$ & $1.627^{* * *}$ & 0.694 & $1.341^{* * *}$ & 1.708 & 0.00 \\
\hline & $25-29$ & $0.56^{* * *}$ & 0.733 & 0.312 & $1.438^{* * *}$ & 2.052 & 0.385 \\
\hline & $30-34$ & $0.716^{* * *}$ & 0.851 & 0.371 & $1.548^{* * *}$ & 1.33 & 1.047 \\
\hline & $35-39$ & $0.764^{* * *}$ & 0.898 & 0.692 & 1.071 & 2.089 & 2.01 \\
\hline & $40-44$ & $0.811^{* * *}$ & 0.907 & 0.626 & 0.911 & 2.271 & 3.692 \\
\hline $\begin{array}{l}\text { Residence } \\
\text { (ref: urban) }\end{array}$ & Rural & $0.686^{* * *}$ & 0.878 & 1.338 & 0.853 & 0.729 & 3.061 \\
\hline \multirow{3}{*}{$\begin{array}{l}\text { Education } \\
\text { (ref: higher } \\
\text { education) }\end{array}$} & No & $0.115^{* * *}$ & 0.455 & 0.154 & 0.907 & 1.33 & $0.006^{* * *}$ \\
\hline & Primary & $0.223^{* * *}$ & 0.635 & 0.195 & 0.195 & 1.395 & 0.01 \\
\hline & Secondary & $0.32^{* * *}$ & 0.392 & 0.158 & 1.408 & 1.071 & 0.17 \\
\hline \multirow{2}{*}{$\begin{array}{l}\text { Has radio } \\
\text { (ref: not } \\
\text { resident) }\end{array}$} & No & 1.414 & 1.255 & 2.474 & 0.776 & 0.838 & $5.243^{* * *}$ \\
\hline & dejure $_{\text {Yes }}$ & $1.67^{* * *}$ & 1.395 & 0.312 & 0.939) & 1.591 & 1.485 \\
\hline $\begin{array}{l}\text { Has television } \\
\text { (ref: yes) }\end{array}$ & No & 0.973 & 0.893 & 0.396 & 1.664 & 1.271 & 2.097 \\
\hline $\begin{array}{l}\text { Has telephone } \\
\text { (ref: yes) }\end{array}$ & No & $0.568^{* * *}$ & 0.827 & 0.838 & 0.619 & 0.838 & 1.568 \\
\hline $\begin{array}{l}\text { Currently working } \\
\text { (ref: No) }\end{array}$ & Yes & $1.121^{* * *}$ & 0.883 & 0.78 & 1.101 & 0.715 & 1.087 \\
\hline \multirow{2}{*}{$\begin{array}{l}\text { Tuberculosis can } \\
\text { cured } \\
\text { (ref: don't know) }\end{array}$} & be Yes & $2.099^{* * *}$ & $0.199^{* * *}$ & 0.878 & 1.857 & $0.654^{* * *}$ & $0.195)$ \\
\hline & No & $3 \cdot 317^{* * *}$ & $3.959^{* * *}$ & 0.158 & $2.552^{* * *}$ & 1.568 & 0.525 \\
\hline \multirow{2}{*}{$\begin{array}{l}\text { Keep secret } \\
\text { (ref: don't know) }\end{array}$} & Yes & $2.521^{* * *}$ & $4.146^{* * *}$ & 1.33 & 1.104 & 0.838 & 3.692 \\
\hline & No & $1.86^{* * *}$ & 3.603 & 0.973 & 1.22 & 1.591) & 0.913 \\
\hline
\end{tabular}

Key: values represent odds ratio; ${ }^{* \pi \pi}$ implies significant at $5 \%$ level otherwise not significant; ref implies reference category

The respondents who resided in rural areas were more likely to accept that TB spreads from person to person through touching person with TB (odd=1.338) and through mosquito bites (odd = 3.061) compared to those from urban areas (Table 5).

Respondents who had works, watching HIV programmes, agreed that tuberculosis can be cured, those who own radio, television and telephone all together showed that were more likely 
to agree that TB spread from person to person through air when coughing compared to their respective reference groups (Table 5).

\section{Discussions}

Generally findings revealed that almost all respondents have heard of tuberculosis and the majority of respondents agreed that the disease is curable. The study showed that majority of the respondents owned radio this is likely to be the most common source of TB information. This implies the radio is an important source of public health information for the majority of people in Tanzania. Similar findings have been reported in India (Palash et al., 2012). The knowledge on tuberculosis transmission increased with an increase in age. However, our results differ from a study in Sudan (Mohamed et al., 2007) where satisfactory knowledge about tuberculosis was inversely proportional with respondent's age. Like in our study, Mohamed et al., (2007) in Sudan found that the knowledge on tuberculosis increases with an increase in level of education. Many respondents in this study had general knowledge about TB which differs with other studies (Khan et al., 2006; Mangesho et al., 2007; West et al., 2008; Tachfouti et al., 2012) that found poor knowledge on TB among many respondents. People from urban areas were more knowledgeable on tuberculosis than their counterparts in rural areas. Similar findings have been reported elsewhere in Tanzania (Kilale et al., 2008). In a study in Vietnam, gender, occupation, economic status, education, and sources of information were significantly associated with level of TB knowledge (Hoa et al., 2009).

The problem of fear and being ashamed to disclose the fact that one member of the family is suffering from tuberculosis observed a small proportion of the respondents. Like in our study, in a study in India, Sreeramareddy et al. (2013) reported that less than a quarter of the study subject would keep it a secret from neighbours if a member of their family got tuberculosis.

In conclusion, the study showed that those with younger ages, lower level of education, people in rural areas, people who did not have television or radio were all less knowledgeable on TB transmission. It is therefore important that more efforts in strengthening public health education are directed to people in rural areas and young individuals taking into account that majority of Tanzanians are living in rural areas and form the largest proportion of the population.

This study based from secondary data obtained from Tanzania HIV/AIDS Indicator Survey in which tuberculosis was only a smaller part of the survey and therefore was limited to few variables related to tuberculosis knowledge and attitudes. The data lacked other important variables like tuberculosis treatments and prevention.

\section{Acknowledgements}

We give much thanks to Tanzania National Bureau of Statistics for helping us with data.

\section{Competing Interest}

Authors have no competing interest.

\section{References}

Dodor, E.A. (2008) Health professionals expose TB patients to stigmatization in society: insights from communities in an urban district in Ghana. Ghana Medical Journal 42, 144-148.

Eram, U., Khan, I. A., Tamanna, M. Z., Khan, Z., Khaliq, N. \& Abidi, A.J. (2006) Patient Perception of Illness and Initial Reaction to the Diagnosis of Tuberculosis. Indian Journal of Community Medicine 31, 198. 
Hoa, N.P., Thi, N., Chuck, K. \& Thorson, A. (2009) Knowledge, attitudes, and practices about tuberculosis and choice of communication channels in a rural community in Vietnam. Health Policy 90, 8-12.

Karim, F., Johansson, E., Diwan, V.K. \& Kulane, A. (2011) Community perceptions of tuberculosis: a qualitative exploration from a gender perspective. Public Health 84, 89.

Khan, J. A., Irfan, M., Zaki, A., Beg, M., Hussain, S. F. \& Rizvi, N. (2006) Knowledge, Attitude and Misconceptions regarding Tuberculosis in Pakistani Patients. J Pak Med Assoc. 56(5):211-4.

Kilale, A.M., Mushi, A.K., Lema, L.A., Kunda, J., Makasi, C.E., Mwaseba, D., Range, N.S. \& Mfinanga, G.S. (2008) Perceptions of tuberculosis and treatment seeking behaviour in Ilala and Kinondoni Municipalities in Tanzania. Tanzania Journal of Health Research 10, 8994.

Mangesho, P.E., Shayo, E., Makunde, W.H., Keto, G.B.S., Mandara, C.I., Kamugisha, M.L., Kilale, A.M. \& Ishengoma, D.R.S. (2007) Community Knowledge, Attitudes and Practices Towards Tuberculosis and its Treatment in Mpwapwa District, Central Tanzania. Tanzania Health Research Bulletin 9, 38-43.

Mohamed, A.I., Yousif, M.A., Ottoa P \& Bayoumi, A. (2007) Knowledge of tuberculosis: a survey among tuberculosis patients in Omdurman, Sudan. Sudanese Journal of Public Health 2, 2128.

MoHSW (2013) The First National Tuberculosis Prevalence Survey in the United Republic of Tanzania. Final Report. Ministry of Health and Social Welfare, United Republic of Tanzania. September 2013.

Palash, D., Mausumi, B., Sinjita, D. \& Debasis D (2012) Perception of Tuberculosis among General Patients of Tertiary Care Hospitals of Bengal. Lung India 29, 319-24.

Ristić, L., Rančić, M. \& Radović, M. (2010) Tuberculosis in the $21^{\text {st }}$ century - challenges, endeavours and recommendations to doctors. Medicinski Pregled 63, 811-815.

Rubel, A.J. \& Garro, L.C. (1992) Social and cultural factors in the successful control of tuberculosis. Public Health Reports 107, 626-636.

Sreeramareddy, C.T., Harsha, H.N., Arokiasamy, J.T (2013) Prevalence of self-reported tuberculosis, knowledge about tuberculosis transmission and its determinants among adults in India: results from a nation-wide cross-sectional household survey. BMC Infectious Diseases 13, 16.

Tachfouti, N., Slama, K., Berraho. M. \& Nejjari, C. (2012) The impact of knowledge and attitudes transmission among ever-married women in Bangladesh. International Journal of Tuberculosis and Lung Disease 15, 379-84.

West, E.L., Gadkowski, L.B., Østbye, T., Piedrahita, C. \& Stout, J.E. (2008) Tuberculosis knowledge, attitudes, and beliefs among north Carolinians at increased risk of infection. North Carolina Medical Journal 69, 14-20.

WHO (2013) TB Fact Sheet No.104: http://www.who.int/mediacentre/factsheets/fs104/en/. 